\title{
RECONSIDERANDO ROBERT COVER: O DIREITO ENTRE SIGNIFICADO E VIOLÊNCIA
}

\author{
Maurício Pedroso Flores*
}

\section{RESUMO}

O presente artigo busca revisitar as principais teses de Robert Cover, jurista norte-americano pouco conhecido no Brasil e cujo pensamento ainda foi pouco explorado dentro da teoria do direito. Considerando o caráter fragmentado de sua obra, o artigo privilegia dois textos considerados centrais para compreender o autor: Nomos e Narrativa, ensaio onde Cover sugere que a criação de significado jurídico (jurisgenesis) transcende os domínios do Estado, e Violência e a Palavra, texto posterior onde o autor considera a indissociabilidade entre a interpretação jurídica e violência. Esses ensaios colocam Cover perante um dilema entre produção e eliminação de significados jurídicos.

Palavras-chave: Robert Cover; nomos; jurisgenesis; violência.

\section{ROBERT COVER RECONSIDERED: LAW BETWEEN MEANING AND VIOLENCE}

\begin{abstract}
This paper aims to reconsider the main theses of Robert Cover, North American jurist barely known in Brasil and whose thinking has been little exploited within the theory of law. Considering the fragmented character of his work, the article privileges two texts that are central to understand the author: Nomos and Narrative - essay where Cover suggests that the creation of legal meaning (jurisgenesis) takes place outside state domain - and Violence and the Word - later text where the author consider legal interpretation and violence as inseparable. These essays place Cover before a dilemma between production and elimination of legal meanings.
\end{abstract}

Keywords: Robert Cover; nomos; jurisgenesis; violence.

\footnotetext{
* Mestre em Direito Público pela Universidade do Vale do Rio dos Sinos (UNISINOS/RS). E-mail: mauriciopflores@gmail.com
} 


\section{INTRODUÇÃO}

Nascido em Boston em 30 de julho de 1943, Robert Cover foi um professor, teórico, ativista e expoente do pensamento jurídico norte-americano, cujos principais escritos remontam à década de oitenta. Cover iniciou sua formação jurídica na Princeton University e concluiu-a na Columbia Law School - onde, logo após se formar, se tornou professor. Após um curto período como professor visitante na Hebrew University em Jerusalém, Cover retornou aos Estados Unidos para assumir o cargo de professor da Yale Law School em 1972, tendo permanecido nessa universidade até sua morte precoce, provocada por um ataque cardíaco, em 18 julho de 1986. Apesar de ter méritos reconhecidos como pesquisador e professor, a experiência de Cover com o direito não esteve restrita à sua formação acadêmica. Fortemente preocupado com as transformações institucionais que o conhecimento pode provocar, Cover participou, durante nove meses, do Student Nonviolent Coordinating Committee (SNCC) - uma das organizações mais importantes do Civil Rights, movimento que buscava o fim da segregação racial legalizada nos Estados Unidos - em uma campanha no estado da Geórgia que alcançou importantes resultados no registro eleitoral de pessoas negras. (CALABRESI et. al., 1987).

Anos depois, já como professor em Yale, Cover participou ativamente de uma campanha organizada por estudantes contra os investimentos da universidade na África do Sul da era do apartheid, e também de piquetes organizados por funcionários da universidade em busca de melhor remuneração e condições de trabalho (WIZNER, 1996, p. 2). Pode-se dizer sem reservas que Cover se tratava de um ativista, um jurista engajado com os conflitos sociais do seu tempo, assim como um professor fortemente preocupado com a prática jurídica. Esse engajamento com questões sociais pode ser lido também em sua obra teórica, cuja concepção de direito reflete um forte compromisso com a transformação da realidade: o direito era, na visão de Cover, um dos principais meios dessa transformação.

Em números, a obra de Cover compreende três livros e cerca de trinta textos menores, divididos entre artigos, resenhas e ensaios. Seu primeiro trabalho de fôlego, o livro Justice Accused, é uma investigação sobre a atmosfera intelectual e os constrangimentos legais que envolviam juízes norte-americanos no tempo da escravidão negra. A obra identifica a presença de um dilema “moral-formal” em que os juízes estavam imbricados: por um lado, a escravidão era uma instituição condenável por autores jusnaturalistas influentes na doutrina da época; por 
outro, a estrutura institucional vigente exigia que a lei positiva fosse respeitada pelos agentes estatais. (COVER, 1975).

Em outros trabalhos, Cover debateu sobre práticas de revisão judicial de programas sociais (COVER, 1967), discutiu as formas de ativismo judicial na defesa de minorias (COVER, 1982), discorreu acerca das possíveis vantagens da sobreposição de jurisdições estaduais e federais no sistema legal dos Estados Unidos (COVER, 1981) e, de forma irreverente, formulou um quiz que relacionava juízes da Suprema Corte a jogadores de beisebol, seu esporte favorito. (COVER, 1995). Apesar de abreviada por sua trágica morte, a fragmentada obra de Cover exerce grande influência sobre a teoria do direito, ainda que essa influência esteja quase que restrita ao seu país de origem. ${ }^{1}$ Mas uma vez que não conseguiu sistematizar seus escritos de uma forma relativamente coerente, o autor deixou a comentadores e críticos muitos questionamentos sobre a sua obra. As diferentes interpretações e apropriações realizadas demonstram que ela ainda é, em grande parte, um livro aberto.

O ponto central do debate em torno de sua obra tem relação com a (des)continuidade presente naqueles que são provavelmente seus textos mais famosos: Nomos e Narrativa (COVER, 1983) e Violência e a Palavra (COVER, 1986b). Pode-se dizer que Nomos e Narrativa foi o ensaio que alçou Cover à condição de teórico do direito. Se esse ensaio não conta com os elementos estruturantes que marcam os grandes tratados sobre direito, Cover oferece em contrapartida um texto denso, carregado de insights que contestam as formas tradicionais de se compreender o fenômeno jurídico. Em um condensado de pouco mais de sessenta páginas, o autor reúne uma ampla gama de leituras e reflexões acumuladas durante anos de estudo. A primeira parte de nosso artigo se ocupa de apresentar as principais teses contidas nesse texto, bem como a centralidade que os conceitos de nomos e jurisgenesis assumem no pensamento de Cover.

Nomos e Narrativa é uma espécie de apelo à teoria e à jurisprudência para que enxerguem a criação do direito para além do Estado, como uma prática essencialmente cultural, enraizada nos atos e compromissos interpretativos assumidos por diferentes grupos e comunidades. Mas não se trata apenas de atentar para a existência de múltiplas normatividades,

\footnotetext{
${ }^{1}$ Para se ter uma noção dessa influência, basta mencionar o fato de que um dos textos mais célebres de Cover, Nomos e Narrativa, foi apontado como o $16^{\circ}$ artigo mais citado em periódicos jurídicos norte-americanos de acordo com o estudo de Shapiro e Pearse (2012). Ademais, o fato de ser citado por autores preocupados com as tendências globalizantes do direito, como Teubner (2016), Benhabib (2006), Berman (2007) e Dunoff (2012), mostra que suas categorias teóricas permanecem úteis para compreender fenômenos jurídicos que o próprio Cover não pode acompanhar, como a formação de uma constelação de regimes jurídicos transnacionais em diversas áreas como economia, ciência, internet, transportes etc.
} 
variadas formas de organizar o espaço normativo (nomos) que habitamos: Cover sugere também que devemos incentivar a proliferação de significados jurídicos como forma de enriquecer os nossos universos normativos.

Mas nem sempre - e aí reside seu grande problema teórico - é possível tolerar normatividades provenientes de fontes sociais diversas sem colocar em risco a própria integridade de um universo normativo. Muitos significados jurídicos são possíveis, mas nem sempre eles são compossíveis - e essa circunstância se torna ainda mais dramática em universos normativos que operam exatamente como o direito ocidental moderno costuma operar: com a presença de um Estado dotado de uma estrutura institucional disposta a tomar comportamentos violentos contra interpretações jurídicas concorrentes.

Porém, em vez de relativizar ou negligenciar essa violência latente, Cover sugere que devemos colocá-la no centro de nossas preocupações. Em Violência e a Palavra, ensaio publicado três anos após Nomos e Narrativa, o autor evoca um "campo de dor e morte” como presente, em maior ou menor medida, em toda interpretação jurídica. As reflexões desse ensaio ocuparão a segunda parte de nossa exposição, compondo uma espécie de antítese ao aparente otimismo com que Cover enxerga a criação de significado jurídico em Nomos e Narrativa. Depois de exaltar a riqueza do nomos, Cover desvela as engrenagens que sustentam a interpretação dos tribunais, chamados por ele de jurispáticos - eles eliminam o direito "em excesso" em nome dos preceitos estatais recorrendo necessariamente à violência, seja ela física (sobre os corpos) ou epistêmica (sobre as interpretações divergentes).

Ao apresentar em linhas gerais o pensamento de Cover, este artigo procura situá-lo em meio ao aparente dilema suscitado pela leitura conjugada entre Nomos e Narrativa e Violência e a Palavra. Mesmo sabendo que essa leitura corre o risco de relativizar alguns aspectos importantes para compreender sua obra, como a profunda influência que os estudos judaicos provocaram no autor, optamos por fornecer aqui uma visão mais sintética de seu pensamento, dando maior relevância àquelas contribuições de Cover que provavelmente são as mais originais para a teoria do direito.

\section{NOMOS E NARRATIVA: A PROLIFERAÇÃO DE SIGNIFICADOS JURÍDICOS}

O primeiro aspecto da visão que Robert Cover possui sobre o direito salta aos olhos logo nas primeiras linhas de Nomos e Narrativa: o direito não se resume ao que o Estado entende - e produz - como direito. A despeito de jamais ter se subscrito ao programa dos 
autoproclamados “pluralistas jurídicos”, é inegável que a obra de Cover parte da constatação de que o direito assume diversas formas em diferentes contextos. Ou seja, Cover se opõe àquilo que John Griffiths (1986, p. 3) denominou como “centralismo jurídico”, isto é, a crença de que o direito é uma "ordem exclusiva, sistemática e unificada de proposições normativas" comumente identificadas com o direito liberal dos Estados modernos. Com grande densidade teórica, o primeiro parágrafo de Nomos e Narrativa ataca a tese do centralismo e convida os leitores a uma revisão radical de suas concepções tradicionais sobre o direito - sua citação por completo é indispensável:

\begin{abstract}
Nós habitamos um nomos - um universo normativo. Nós constantemente criamos e mantemos um mundo de certo e errado, lícito e ilícito, válido e inválido. O estudante de direito pode chegar a identificar o mundo normativo com a parafernália profissional do controle social. As regras e princípios de justiça, as instituições formais do direito e as convenções de uma ordem social são, de fato, importantes para esse mundo; contudo, elas são apenas uma pequena parte do universo normativo que deveria chamar nossa atenção. Nenhum conjunto de instituições ou preceitos legais existe separado das narrativas que o situam e lhe dão sentido. Para cada constituição há um épico, para cada decálogo uma escritura. Uma vez entendido no contexto das narrativas que lhe dão sentido, o direito se torna não apenas um sistema de regras a serem observadas, mas um mundo no qual vivemos. ${ }^{2}$ (COVER, 1983, p. 4).
\end{abstract}

A quantidade de informações trazidas por Cover nos impele a uma análise minuciosa desse parágrafo. Em primeiro lugar, cumpre destacar o objeto de estudo estabelecido pelo autor: estudar direito significa estudar o universo normativo que ele cria. O direito é uma forma de organizar o mundo através de classificações do tipo certo/errado ou, conforme a linguagem propriamente jurídica ${ }^{3}$, válido/inválido e lícito/ilícito. Essas distinções operam na realidade para manter ou modificar determinados estados de coisas, e quando nossas ações são empregadas com essas finalidades elas passam, automaticamente, a fazer parte do universo normativo. Em suma, o direito dá vazão a um nomos, um mundo normativo que é "tão 'nosso mundo' quanto o universo físico de massa, energia e movimento". (COVER, 1983, p. 5).

Embora a afirmação de que nós habitemos um nomos seja anterior a qualquer argumentação dentro do texto, Cover evidentemente não concebeu esse universo normativo por pura obra da sua imaginação. Boa parte da densidade de Nomos e Narrativa - assim como de seu primeiro parágrafo - se deve à presença de argumentos e pressupostos que o autor não explicita no texto. Um dos pressupostos mais importantes remete à sociologia do conhecimento

\footnotetext{
2 Todas as traduções do inglês são livres.

${ }^{3}$ Com isso queremos dizer que o par certo/errado pode pertencer ao campo da moral, o que não ocorre com os outros dois, cujo uso é específico do tipo de regulação de conduta estabelecido pelo direito. Para Cover, no entanto, a distinção certo/errado também faz parte do mundo jurídico.
} 
de Peter Berger e Thomas Luckmann (2007). Em A construção social da realidade, Berger e Luckmann procedem a uma investigação sociológica sobre os fundamentos do conhecimento na vida cotidiana. Sua tese principal, como o próprio título do livro sugere, é a de que a humanidade constrói a sua própria realidade por meio de processos sociais institucionalizados e legitimados historicamente. De acordo com os autores, "mais do que possuir uma natureza, nós construímos nossa própria natureza” (BERGER; LUCKMANN, 2007, p. 70), produzindo um ambiente humano que costumamos chamar de ordem social ou sociedade. A partir do entendimento de que nós construímos nossa própria natureza, instituições como a família ou o direito passam a ser vistas não como condicionantes prévias de nossa existência, mas como artefatos sociais historicamente variáveis que organizam nossa experiência em um mundo que não nos é simplesmente “dado”, mas construído - em alguma medida por nós, em outra por nossos ancestrais. Cover certamente vê o direito, em sua formulação mais elementar, como uma instituição social. Apesar de simples, esse é talvez o grande pressuposto de Nomos e Narrativa, que permite a Cover descrever o direito em boa parte como um processo de criação de significado (jurisgenesis) e situar a sua base social em torno da construção de narrativas sobre o mundo.

Para Cover, a narrativa é o próprio ato de imposição de uma força normativa na realidade. O direito é visto assim como um "sistema de tensão ou uma ponte ligando um conceito de realidade a uma alternativa imaginada" (COVER, 1983. p. 9), ou seja, representa uma tensão entre dois estados de coisas, um presente e um futuro - ambos passíveis de representação por meio de dispositivos narrativos. Ao funcionar como uma ponte entre presente e futuro, o direito tal como concebido por Cover não é inteiramente realidade social e nem normatividade pura (ETXABE, 2010, p. 122). O nomos é assim "um mundo presente constituído por um sistema de tensão entre realidade e visão” (COVER, 1983, p. 9). Se o elemento do nomos da realidade é trazido à tona pela narrativa, Cover sugere que o elemento representado pela visão corresponde ao fenômeno que George Steiner (2005) denominou como alternidade (COVER, 1983, p. 9). O conceito de alternidade busca dar conta da nossa capacidade de articular, de forma preponderantemente verbal, "mundos outros que não este” (STEINER, 2005, p. 243). A alternidade significa, portanto, o “outro que não o que é”, ou seja, "as proposições contrafactuais, as imagens, as formas de vontade e de evasão com as quais energizamos nossa existência mental e construímos o meio cambiante, amplamente fictício de nossa existência somática e social” (STEINER, 2005, p. 242). Com a alternidade, Cover acrescenta à clássica distinção ser/dever ser (fato/norma) uma terceira categoria ontológica: o 
direito não é apenas o que é e o que deveria ser, mas também o que poderia ser. Ao pensar o direito em termos do que ele "poderia ser", o autor demonstra uma sensibilidade sociológica em relação às diferentes ordens normativas presentes na sociedade. O direito é uma ponte ou, como Cover (1985, p. 181), formulou de maneira simples em outro texto, “comportamento social comprometido que constitui a forma por meio da qual um grupo de pessoas procura ir daqui para lá" - ou seja, do "aqui” da realidade existente para o "lá” de uma alternativa imaginada.

Contudo, o elemento da alternidade não deve alimentar ilusões quanto à realidade existente: se fosse mera possibilidade ou imaginação, o direito cairia facilmente na utopia ou na pura visão ${ }^{4}$. As narrativas oferecem modelos de ação ${ }^{5}$, mas nem sempre esses modelos são realizáveis. Se determinada visão não for capaz de fornecer o contexto para uma ação humana viável, então ela não é, de acordo com Cover, uma narrativa propriamente jurídica:

\begin{abstract}
Se o direito reflete uma tensão entre o que é e o que pode ser, então ele só pode ser mantido enquanto ambos estiverem próximos o suficiente para revelar uma linha de esforço humano capaz de reconciliá-los de forma temporária ou parcial. Todos os movimentos utópicos ou escatológicos que não se afastam da insularidade arriscam falhar em converter a visão em realidade e, portanto, rompem a tensão. Nesse ponto, eles podem até ser movimentos, mas não são mais movimentos do direito. (COVER, 1983, p. 39).
\end{abstract}

Somente dessa forma o direito "mantém nossa realidade apartada de nossas visões e nos resgata da escatologia que é a colisão das construções de nossas mentes com o mundo material e social” (COVER, 1983, p. 10). Essa ressalva em relação à especificidade da narrativa jurídica é importante, uma vez que a amplitude do modelo inicial de Cover - um universo normativo baseado em noções de certo e errado - pode levar a interpretações equivocadas. Ao eliminar do âmbito do direito as narrativas incapazes de mobilizarem a ação humana, o autor reduz significativamente esse universo. Mas é preciso ir além, é preciso compreender colocando de uma forma mais direta - como se faz direito. É aqui que Cover defende o seu conceito de jurisgenesis como forma de explicar a origem da normatividade social:

O nomos que descrevi não requer Estado. E de fato, é a tese desse ensaio que a criação de significado jurídico - “jurisgenesis” - acontece sempre através de um meio essencialmente cultural. Embora o Estado não seja necessariamente o criador do

\footnotetext{
${ }^{4}$ Esse é um possível ponto de divergência entre as concepções de Cover e as que Steiner identifica como sendo pertencentes a Ernst Bloch, para quem o instinto utópico é a mola da política. (STEINER, 2005, p. 237).

5 “Narrativas são modelos de ação por meio dos quais estudamos e experenciamos transformações que acontecem quando um dado estado de coisas simplificado é forçado a passar através do campo de força de um conjunto de normas igualmente simplificado.” (COVER, 1983, p. 10).
} 
significado jurídico, o processo criativo é coletivo ou social. Na seção a seguir, sugiro uma base social para a jurisgenesis e uma base social correspondente para o processo que destrói significado jurídico por interesse do controle social. (COVER, 1983, p. 11).

Como vimos no primeiro parágrafo, as regras e instituições formais do Estado são apenas parte do universo normativo concebido em Nomos e Narrativa. Contudo, ao tratar do processo de jurisgenesis, Cover vai além: afirma que o direito estatal sequer é necessário para que o nomos exista. A gênese do significado jurídico encontra-se nas práticas culturais, e não na formação de instituições oficiais. Disso se segue que o Estado não possui qualquer privilégio hermenêutico na criação do direito; suas intepretações não são qualitativamente melhores do que a de grupos e comunidades que articulam seus próprios entendimentos jurídicos. Mas então por que o Estado é quem, em última instância, decide os conflitos sobre o direito? Por que as decisões judiciais possuem autoridade para vincular indivíduos e grupos às suas interpretações legais?

Cover tem uma resposta muito simples a essa questão: a posição de centralidade que o direito estatal costuma assumir se dá unicamente porque o Estado é capaz de garantir, através da violência, o comprometimento necessário para a afirmação dos significados jurídicos que ele próprio considera corretos. Essa violência é comumente negligenciada pela teoria do direito, que tende a naturalizar o recurso da coerção legal como legítimo. A decisão judicial costuma ser o limite da reflexão teórica sobre a interpretação legal - há modelos de racionalidade jurídica que procuram orientar o julgador, há teorias da prova e da argumentação. No entanto, uma vez que o julgamento é proferido, as teorias da intepretação se calam. Não há mais qualquer tipo de questão a ser levantada. Terminado o processo, a sentença judicial se esgota em um imperativo: “cumpra-se”. O que vem depois já não pertence ao campo da teoria.

Cover acredita que essa é uma atitude problemática. A seu ver, não se pode negligenciar a existência de uma estrutura de cooperação - formada por oficiais de justiça, policiais, agentes penitenciários - incumbida de dar efeito prático às sentenças; sem ela, afirma o autor, a palavra do juiz não teria mais autoridade que a interpretação de um crítico literário. Cover desenvolverá esse raciocínio de forma mais aprofundada em Violência e a Palavra, conforme a seguir. Por ora, cumpre atentar a uma distinção que decorre do estado de coisas descrito pelo autor: em termos de organização social do direito, existe uma dicotomia radical entre o direito como poder e o direito como sentido. (COVER, 1983, p. 18).

Os preceitos legais (inclusive os formalmente instituídos) devem possuir sentido, mas esse sentido provém necessariamente de fora do processo legislativo formal ao qual se confere 
poder (COVER, 1983, p. 18). Ao entender que o direito é inicialmente sentido, o modelo de Cover é capaz de identificar como jurídicos alguns discursos ou manifestações tipicamente classificadas como éticas, morais ou religiosas. Um grupo ou comunidade ${ }^{6}$ que se proclame autônomo (ou seja, que literalmente cria um nomos próprio) em relação ao Estado não possui, por exemplo, uma visão ética ou religiosa particular sobre determinado preceito constitucional; possui, na verdade, outro direito. Mas isso evidentemente levanta uma questão: todo grupo social pode afirmar que possui um direito próprio - um nomos que possa chamar de seu? Cover não parece oferecer um critério fechado nesse aspecto. ${ }^{7}$ Julen Etxabe (2010) encontra, no entanto, ao menos quatro características comuns a todos os exemplos fornecidos pelo autor em Nomos e Narrativa: a formação de um nomos parece pressupor um grupo humano bem constituído, uma autoconsciência em relação à identidade do grupo, uma percepção de compartilhamento e delimitação baseada em textos comuns e determinados projetos de vida normativos. (ETXABE, 2010, p. 122).

Contudo, para além das características, é possível afirmar que o conceito de jurisgenesis, para além de seu apelo a uma visão não estritamente estatal sobre o direito, também parece exercer uma função de “qualificação” das narrativas no pensamento de Cover como efetivamente jurídicas. Como já mencionamos, o primeiro passo é separar planos de ação realizáveis de expectativas ilusórias ou utopias puras. Não basta afirmar que podemos ir de um “aqui” para um "lá”; é preciso mostrar como. Para além da interpretação, o significado jurídico necessita, na visão de Cover, também de comprometimento. O comprometimento vai além da narrativa, além da visão que projetamos sobre a realidade - trata-se do esforço necessário para se chegar até elas. A construção de universos normativos só é possível na medida em que se colocam, conforme a expressão que Cover utilizará em Violência e a Palavra, os “corpos à

\footnotetext{
${ }^{6}$ Falamos em "grupo ou comunidade" porque, na visão de Cover, o nomos é necessariamente um processo social, e nunca individual. Um indivíduo certamente pode formular uma interpretação jurídica própria, e pode até conseguir viver sob ela. Nesse caso, contudo, não haveria qualquer processo social envolvido. A menos que se torne inteligível a uma comunidade mais ampla e possa constituir um modelo de comportamento adotável, essa intepretação constitui por si só um nomos. Nesse sentido, argumenta Cover: "Qualquer pessoa que tivesse uma vida normativa inteiramente idiossincrática seria bastante louca. O papel que você ou eu escolhemos assumir pode ser singular, mas o fato de que nós podemos situá-lo em um 'script' comum o torna 'são' - é uma garantia de que nós compartilhamos um nomos.” (COVER, 1983, p. 10).

${ }^{7}$ Uma objeção provável aqui é: seguindo essa lógica, devemos considerar que um grupo terrorista também pode constituir um nomos. E de fato, a resposta seria afirmativa - não se pode dizer que o Estado Islâmico, por exemplo, não possua suas próprias interpretações e não se comprometa (de uma forma extrema, devemos dizer) com elas. Mas disso não se segue que, reconhecendo um nomos, devemos necessariamente preservá-lo. Cover não chegou a tratar especificamente dessa questão, mas pode se concluir, a partir de sua discussão sobre a violência do direito estatal, que um nomos não deve impor seus preceitos de maneira violenta, declarando qualquer manifestação alternativa como inimiga - como é o caso das manifestações extremistas do tipo "guerra justa”.
} 
prova (bodies on the line)” (COVER, 1986b, p. 1605). Ou seja, o significado jurídico depende de uma narrativa relativamente estável, com a qual seja possível se compreender de modo a torná-la realidade objetiva para os demais atores sociais envolvido. Interpretação, comprometimento e objetivação - na falta de algum desses três elementos não é possível, segundo Cover, falar em direito.

A manifestação arquetípica presente em Nomos e Narrativa é o nomos criado por uma comunidade religiosa que vive conforme suas próprias intepretações de textos sagrados. Além da clara influência que as narrativas bíblicas exercem no pensamento de Cover, a centralidade

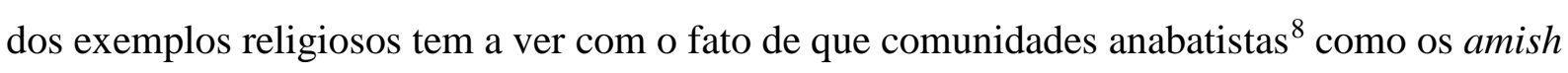
e os menonitas manifestaram-se como amicus curiae no caso analisado pelo autor, o Bob Jones University. Esses exemplos também se encaixam perfeitamente na descrição fornecida por Cover sobre a base social da jurisgenesis. Do lado das comunidades, verifica-se um processo de criação do direito; do ponto de vista do tribunal, interessa a estabilização dos significados jurídicos aceitos pelo Estado. Diante dessa contraposição de forças, o autor aponta para a existência de dois modelos distintos de constituição do nomos.

Cover denomina o primeiro tipo como paideico. Nesse modelo, de forte inspiração religiosa, grupos ou comunidades articulam seu próprio espaço normativo a partir de determinado corpo de preceitos e narrativas e um sentido de unidade entre seus membros. A possibilidade de novas interpretações encontra-se permanentemente aberta, e o direito assume um caráter pedagógico: os indivíduos são educados na lei, de modo que a obediência é fruto de um processo de entendimento, e não de coerção normativa (COVER, 1983. p. 12-13). O vínculo entre os indivíduos é de obrigação recíproca e de responsabilidade individual com o bem-estar geral do grupo. Já ao segundo modelo, responsável mais por manter os universos normativos do que criá-los, Cover dá o nome de imperial. Esse modelo caracteriza-se pela objetividade de seus preceitos - normas jurídicas abstratas e universais - e pelo fato de que sua aplicação fica a cargo de instituições devidamente constituídas para esse fim. Os compromissos interpessoais são fracos, uma vez que só se exige que os indivíduos evitem determinados tipos de condutas legalmente reprováveis. É como o direito moderno funciona em sua maior parte; uma forma de garantir que o nomos não se desintegre em razão de suas tendências plurais e potencialmente

\footnotetext{
${ }^{8}$ A origem dessas comunidades cristãs sectárias remete à ala mais radical (e também a mais perseguida) da Reforma Protestante, que propunha, entre outros aspectos, a "re-batização", ou seja, que a cerimônia do batismo fosse repetida na idade adulta, quando o indivíduo pudesse realizar o ato de forma consciente. Ainda que em número bastante reduzido, essas comunidades sobrevivem até hoje em colônias espalhadas por diversas partes do mundo.
} 
destrutivas, tornando possível a difícil tarefa de acomodá-las dentro de um mesmo espaço normativo. (COVER, 1983, p. 13). É importante destacar, no entanto, que nenhum universo normativo é criado ou mantido somente por meio do modelo paideico ou do modelo imperial. Ambos funcionam como tipos ideais na análise de Cover; não representam sociedades de fato, mas bases coexistentes de atributos distintos presentes em cada uma delas (COVER, 1983, p. 14). No contexto dos estados-nação modernos, o modelo imperial encontra-se intimamente ligado à organização social dos preceitos legais (direito como poder), enquanto o paideico parece mais próximo da organização social das narrativas que sustentam esses preceitos (direito como sentido). (COVER, 1983, p. 16).

Quando o processo de jurisgenesis tem lugar no interior dos Estados, o parâmetro que irá orientar a prática do controle social será o texto constitucional ${ }^{9}$. Mesmo que o respeito à Constituição muitas vezes implique na eliminação de intepretações incompatíveis com seus preceitos, é possível conceber, segundo Cover, um processo de criação de sentido constitucional, que tende a assumir também duas formas distintas. Quando determinadas comunidades autônomas - como os anabatistas, por exemplo - buscam constituir um nomos próprio, a jurisgenesis assume uma forma denominada autonomia insular. Nesses casos, as comunidades com pretensões de isolamento estabelecem significados próprios para interpretar os princípios constitucionais dos Estados onde se localizam. As comunidades religiosas mencionadas por Cover procuram respeitar as normas do Estado, mas negam que ele detenha o monopólio da interpretação sobre o direito. Quando não há qualquer pretensão de constituir um universo normativo próprio, mas de transformar o significado constitucional dentro do próprio âmbito estatal, a jurisgenesis assume outra natureza, batizada por Cover de constitucionalismo redentor. Esse registro compreende grupos e instituições que procuram modificar o direito a partir de diferentes narrativas sobre a realidade, com objetivos integrativos, e não sectários (COVER, 1983, p. 34). É o caso, por exemplo, das lutas por direitos encabeçadas por movimentos sociais, que se apropriam da gramática jurídica estatal em suas reivindicações.

Ao longo de Nomos e Narrativa, Cover continuamente reitera que o nomos ao qual o direito dá vazão ultrapassa os contornos oficiais do Estado. Mas não se deve interpretar isso como uma tentativa desesperada de escapar de qualquer tipo de controle institucional, em favor de um direito “anárquico”. A interpretação jurídica não é absolutamente livre, uma vez que

\footnotetext{
9 “Em nosso próprio mundo normativo, não há um texto obviamente central, certamente nenhum que forneça as narrativas e os preceitos de forma exaustiva. Não obstante, a constituição dos Estados Unidos se autodeclara como 'lei suprema'.” (COVER, 1983, p. 25). Não há dúvidas que essa afirmação também se impõe no contexto constitucional brasileiro, em que pese a presença de normas derivadas de tratados internacionais, por exemplo.
} 
[...] o princípio da jurisgenesis pelo qual o significado jurídico se prolifera em todas as comunidades jamais existe isolado da violência. A interpretação sempre se dá à sombra da coerção. E a partir desse fato podemos reconhecer um papel especial para os tribunais. Os tribunais, ao menos os estatais, são caracteristicamente “jurispáticos”. (COVER, 1983, p. 40).

O tribunal é o lugar onde as narrativas de grupos ou comunidades, que Cover chama de "textos de resistência”, são confrontadas com as narrativas da ordem jurídica, ou seja, os “textos da jurisdição” (COVER, 1983, p. 54). Mas o caráter aparentemente textual dos conflitos não deve mascarar os aspectos que o autor considera como os mais problemáticos no domínio do significado: a força e a violência. Sua preocupação maior não é, portanto, com o fato de que tribunais existam; mas sim com o potencial violento que suas interpretações comportam. E o motivo dessa preocupação tem a ver com a formulação original de Cover sobre por que os tribunais existem. Segundo o autor, os apologistas modernos da jurisdição colocam a questão da existência dos tribunais como um problema de incerteza do direito; o papel dos tribunais seria o de esclarecer as ambiguidades ou opacidades presentes no ordenamento jurídico (COVER, 1983, p. 42). Cover, por outro lado, acredita que o problema que se apresenta aos tribunais não é a existência de direito incerto, mas de direito em demasia - consequência da capacidade inesgotável da jurisgenesis. A multiplicidade de interpretações legais é o problema para o qual os tribunais representam a solução. (COVER, 1983, p. 40).

O trabalho dos juízes é ambíguo, pois envolve ao mesmo tempo violência e paz. Cover sugere que, diante desse estado de coisas, somente um comprometimento efetivo dos tribunais com o problema da violência é capaz de lidar com essa ambiguidade:

\footnotetext{
Os juízes são pessoas de violência. Por conta da violência que comandam, os juízes caracteristicamente não criam direito, mas o eliminam. Seus escritórios são jurispáticos. Enfrentando o exuberante crescimento de uma centena de tradição legais, eles afirmam que apenas uma é direito e destroem ou tentam destruir o resto. Mas os juízes também são pessoas de paz. Entre seitas antagônicas, cada uma delas envolta no manto de seu próprio direito, eles afirmam uma função reguladora que permite uma vida de direito ao invés de violência. A extensão da violência que eles poderiam comandar (mas geralmente não comandam) mede a extensão da paz e do direito que eles constituem. (COVER, 1983, p. 53).
}

Cover parece enunciar o problema de forma bastante clara. No entanto, sua reflexão parece longe de pretender solucioná-lo. Mesmo com um aprofundamento posterior, em Violência e a Palavra, a reflexão do autor sobre a violência dos tribunais não escapará de 
críticas bastante razoáveis. Deixando essa questão em aberto, Nomos e Narrativa se encerra com a seguinte mensagem:

\begin{abstract}
Não é o romance da rebelião que deveria nos levar a olhar para o direito desenvolvido por movimentos sociais e comunidades. Bem pelo contrário. Assim como é a nossa desconfiança e o reconhecimento do Estado como realidade que nos leva a ser constitucionalistas no que diz respeito a ele, então o nosso reconhecimento e desconfiança em relação à realidade do poder dos movimentos sociais que deveria nos levar a examinar os mundos nômicos que eles criam. E assim como o constitucionalismo é parte daquilo que pode legitimar o Estado, da mesma forma o constitucionalismo pode legitimar, dentro de uma estrutura distinta, comunidades e movimentos. O significado jurídico é um enriquecimento desafiador da vida social, enriquecimento desafiador da vida social, uma potencial limitação ao poder arbitrário e à violência. Nós devemos parar de circunscrever o nomos; nós devemos recepcionar novos mundos. (COVER, 1983, p. 68).
\end{abstract}

Esse último parágrafo de Nomos e Narrativa, que incentiva a proliferação de significados jurídicos, é também um apelo por um direito menos violento. Como veremos a seguir, ao tratar de Violência e a Palavra, esse apelo é sucedido por uma análise bem mais fria e modesta sobre as possibilidades de separar o direito do arbítrio e da violência, o que fez alguns comentadores sugerirem que as mensagens dos dois ensaios são, em certa medida, contraditórias.

\title{
3 VIOLENNCIA E A PALAVRA: O CONTROLE SOCIAL SOBRE O SIGNIFICADO
}

Se Nomos e Narrativa procura contestar os pressupostos das teorias do direito centradas fundamentalmente no Estado, o alvo de Violência e a Palavra é a naturalidade com que essas teorias legitimam o exercício da violência sob o manto da jurisdição. Em suma, Cover assume aqui a tarefa de explicitar a relação entre o trabalho intelectual dos juízes e juízas e as consequências materiais que esse trabalho produz na realidade. O tom do primeiro parágrafo é, como de costume, carregado - e mostra imediatamente o que está em jogo quando falamos da interpretação jurídica no âmbito jurisdicional:

A interpretação jurídica tem lugar em um campo de dor e morte. Isso é verdade em
vários sentidos. Os atos de interpretação jurídica sinalizam e ocasionam a imposição
de violência sobre outros: um juiz articula seu entendimento de um texto e, como
resultado, alguém perde sua liberdade, sua propriedade, seus filhos - até mesmo sua
vida. As intepretações no direito também constituem justificativas para a violência
que já ocorreu ou está prestes a ocorrer. Quando os intérpretes terminam seu trabalho,
frequentemente deixam para trás vítimas cujas vidas foram despedaçadas por essas
práticas de violência social organizada. Nem a interpretação jurídica nem a violência
que ela ocasiona podem ser propriamente entendidas separadas uma da outra.
(COVER, 1986b, p. 1601). 
Cover (1986b, p. 1601) considera que a violência presente na interpretação jurídica é um fato óbvio, mas aparentemente ignorado pela “crescente literatura que argumenta em favor da centralidade das práticas de interpretação no direito”. O autor coloca James Boyd White e Ronald Dworkin como as maiores referências da literatura “interpretativista” que despontava com força dentro da teoria do direito da época. Mas o que preocupa Cover em relação a esses autores - como em todos aqueles que situam a questão da interpretação no centro do direito é o fato de que o lado violento do direito costuma ser negligenciado ou ignorado em suas análises. Nesse aspecto, White foi quem chegou mais próximo de uma crítica da violência; mas ao pensar o direito fundamentalmente como um sistema de constituição retórica, relegou-a a um papel secundário. Cover reconhece esse esforço, mas não se mostra totalmente satisfeito com ele: "não nego que o direito seja todas essas coisas que White afirma que é, mas eu insisto que o direito é todas essas coisas no contexto de uma prática social organizada de violência”. (COVER, 1986b, p. 1602).

O “campo de dor e morte” que Cover evoca na primeira linha de Violência e a Palavra é uma forma de mostrar a radicalidade do problema. Só em parte é metáfora, uma vez que é a realidade presente - e frequentemente disfarçada - em alguns dos mais simples e corriqueiros atos judiciais, como as sentenças criminais, por exemplo. A intenção do autor é mostrar que tipo de compromisso com a violência se esconde por trás da "fachada de civilização" (COVER, 1986b, p. 1607) que a estrutura da interpretação jurídica e do ato de julgar costumam produzir.

Dificilmente algum teórico do direito discordaria que há diferenças entre a interpretação jurídica e a interpretação filosófica ou literária, por exemplo. Mas Cover pretende mostrar que a presença da violência acentua essa diferença de tal forma que a interpretação jurídica, ainda lembre a interpretação literária em certos aspectos de construção mental, é no entanto extremamente peculiar em seu potencial de transformação da realidade e deve, por essa razão, ser entendida de acordo com sua lógica própria - uma lógica que carrega as marcas de uma violência presente ou futura. ${ }^{10}$

Essa diferença é válida tanto para a interpretação estritamente judicial, da qual Cover se ocupa em Violência e a Palavra, como para a interpretação jurídica em sentido mais amplo, resultado dos processos de jurisgenesis em grupos e comunidades menores, conforme a

\footnotetext{
${ }^{10}$ Em The Bonds of Constitutional Interpretation, Cover assinala radicalmente a diferença entre a interpretação no contexto judicial e no contexto literário ou filosófico: “A prática da interpretação constitucional é tão inextrincavelmente ligada à ameaça real ou à prática de atos violentos que ela é - e deveria ser - uma disciplina essencialmente diferente da ‘interpretação’ na literatura e nas humanidades”. (COVER, 1986a, p. 816).
} 
descrição feita em Nomos e Narrativa. Nesse último caso, a despeito do privilégio que o próprio autor concede ao papel da construção de sentido ou de realidades alternativas, não se pode esquecer que mesmo a jurisgenesis não estatal tem de prestar contas com a violência, uma vez que "todo grupo deve acomodar no seu próprio mundo normativo a realidade objetiva do outro" (COVER, 1986a, p. 28-29). Adotando um tom mais passional, característico de uma conferência, Cover reforça essa ideia ao final de The Bonds of Constitutional Interpretation:

No direito, ser um intérprete é ser uma força, um ator que cria efeitos mesmo através ou em face da violência. Hesitar diante do sofrimento ou da imposição de violência é entregar o direito para aqueles que estão dispostos a agir desse modo. O Estado é organizado para superar escrúpulo e medo. Todos os outros serão meros peticionários se não atacarem de volta. (COVER, 1986a, p. 833).

Para Cover, o lugar central da interpretação jurídica não é o texto, mas um campo de batalha. Trata-se de uma interpretação que "envolve instrumentos tanto da guerra como da poesia” (COVER, 1986a, p. 817). Isso não deve significar o fim de qualquer aspiração constitucional de enfrentar a violência, mas apenas o fim das visões excessivamente românticas sobre a constituição. Se há algo de romântico nas visões que Cover invoca em Violência e a Palavra, também há, em igual ou maior medida, algo de violento em cada uma delas. Para Cover, o ato de sentenciar um réu pode fazer parte do cotidiano de qualquer juiz, mas ainda assim “é imensamente revelador sobre o modo como a interpretação é marcada de forma distinta pela violência”. (COVER, 1986b, p. 1607). Porém, quem espera a seguir uma condenação veemente da violência por parte de Cover, se depara com uma inusitada afirmação: "Se posso ter mostrado algum tipo de simpatia em relação às vítimas dessa violência, trata-se de um engano. Com grande frequência o equilíbrio de terror é, nesse tipo de situação, justamente como eu queria que fosse” (COVER, 1986b, p. 1608). Essa passagem é sintomática de uma ambiguidade que persiste ao longo do ensaio, e que pode ser resumida da seguinte forma:

Em Cover nós encontramos tanto um crítico como um apologista da violência; encontramos uma insistência para que o direito seja diferente da violência, e mais do que ela - e de que o direito guie a sociedade humana em direção à tolerância, ao respeito e à comunidade, combinada com uma relutante adoção da força jurídica. Em Cover nós encontramos um autoproclamado anarquista [...] que, no entanto, procura identificar as condições para uma efetiva, mas domesticada, organização e emprego da violência do direito. (SARAT; KEARNS, 2001, p. 50).

Se em Nomos e Narrativa os juízes são retratados ao mesmo tempo como “pessoas de violência” e “pessoas de paz” (COVER, 1983, p. 53), Cover os coloca aqui sentados sobre “uma 
pirâmide de violência” (COVER, 1986b, p. 1609), “distribuindo dor e morte”. Há uma justificativa para essa mudança de ênfase, como o próprio autor explica: "Escrevi em outra oportunidade que os juízes estatais são jurispáticos [...] Aqui, no entanto, não estou escrevendo sobre a qualidade jurispática do ofício, mas sobre seu potencial homicida.” (COVER, 1986b, p. 1610). Ou seja, Cover não está tratando da possível eliminação de interpretações jurídicas, mas de corpos. Ao menos no sistema norte-americano, juízes são capazes de ordenar execuções por meio do direito. Podemos dizer que, de uma forma ou de outra, o direito - ao menos em sua formulação estatal - sempre conterá esse potencial homicida, haja vista a estrutura de coerção que lhe dá sustentação. O poder de praticar violência física lhe é tão intrínseco que não necessita de previsões constitucionais expressas - ele parece subentendido na própria ideia de governo. (COVER, 1986b, p. 1610).

Se Cover não se contrapõe de imediato a esse fato, isso não quer diz que ele considere as interpretações jurídicas como algo mais importante que pessoas de carne e osso; ele pretende somente enfatizar que há diferenças, em termos funcionais, entre o fato de se executar pessoas por meio de estruturas físicas e de se eliminar interpretações jurídicas por meio de atividades mentais. Seu foco não é saber se a violência dos juízes é ou não legítima; trata-se de reconhecêla como um fato e, a partir disso, descrever suas características de funcionamento. Em termos gerais, a interpretação jurídica é vista por Cover como “1) uma atividade prática, (2) desenhada para gerar ameaças críveis e atos reais de violência, (3) de maneira efetiva” (COVER, 1986b, p. 1610). Sua descrição da violência estatal opera com base na análise de cada um desses três elementos.

Mas essa descrição não tem o caráter de mera denúncia do poder: ao longo de sua engenhosa argumentação, Cover termina por sugerir que a capacidade de coordenação da prática de violência deva ser vista como uma “conquista” de nossos sistemas jurídicos na tarefa de "domesticar” a violência do direito. E esse argumento aparece com ainda mais força quando o autor trata das sentenças capitais - que, segundo ele, revelam a estrutura da interpretação judicial sob um grau extremo, como uma questão de vida ou morte (COVER, 1986b, p. 1623). Uma vez que esse ato é irreversível, a palavra judicial assume um peso maior do que em outros casos - circunstância que explica de certa forma as intermináveis discussões sobre a possibilidade ou a aplicabilidade da pena de morte. Cover opta por não tomar partido nessa discussão; mas, recordando épocas sombrias em que o linchamento era uma prática comum nos Estados Unidos, prefere enfatizar o progresso do sistema de cooperação desenvolvido para o tratamento jurisdicional dessa questão: 
O fato é que temos percorrido um bom caminho, desde 1914, no que diz respeito a nossas expectativas de que as pessoas acusadas de crimes capitais tenham um julgamento, sejam apropriadamente sentenciadas e vivam para ver o tempo marcado para a execução de sua sentença. De fato, hoje esperamos uma coordenação quase perfeita entre aqueles cujo papel seja o de infligir violência, sujeita às decisões interpretativas dos juízes. Esperamos inclusive uma cooperação coordenada de modo a assegurar todas as interpretações jurídicas plausíveis sobre o assunto. Uma forma bem coordenada da violência como essa é uma conquista. Os delicados compromissos sociais destinados a executar essa violência que é a punição capital, ou para evitar esse ato, não são produtos fortuitos ou casuais das circunstâncias. (COVER, 1986b, p. 1624-1625).

O raciocínio de Cover parece contraintuitivo: como alguém pode falar da pena de morte em termos da "conquista” representada pela sua efetiva coordenação? De forma um tanto inusitada, o autor parece sustentar aqui que a violência do direito, ao promover compromissos que escapam dos produtos “fortuitos” das circunstâncias, seja uma espécie de forma superior de violência. A defesa dessa interpretação não chega a ser novidade na teoria do direito, ao menos para aqueles que consideram que a violência, quando executada conforme procedimentos juridicamente instituídos, carrega algo de “legítimo”. Mas o que Cover pretende mostrar aqui é que esse caráter de legitimidade não está relacionado a qualquer tipo de interpretação que enxergue no juiz uma espécie de “voz da razão”. Não se trata de possuir a melhor interpretação possível, ou o melhor entendimento entre textos constitucionais e sociais a que um Hércules hipotético pode almejar. Cover reconhece que construções como a de Dworkin podem até ser úteis para compreender a atividade dos juízes enquanto deliberação mental. Mas é preciso pensar a forma como suas convicções são traduzidas, por meio da ação de outros, em atos. E para que isso aconteça, a circunstância mais fundamental é a de que as palavras judiciais carreguem "o indício formal de terem sido pronunciadas na investidura do juízo”; é essencial, portanto, que esteja claro dentro da estrutura institucional "quem fala como juiz e quando isso acontece” (COVER, 1986b, p. 1625).

Mas há, na visão de Cover, outra circunstância igualmente fundamental para que a violência no direito se afaste o máximo possível da violência pura: nenhum juiz deve ter, sozinho, a última palavra sobre o significado jurídico diante de casos concretos. Cover reflete sobre tal circunstância da seguinte forma:

Nós fizemos algo estranho em nosso sistema. Nós separamos rigidamente o ato de interpretação - de compreensão do que deveria ser feito - da execução "do que deveria ser feito” por meio de violência. Ao mesmo tempo, ao menos no direito penal, estabelecemos uma rígida conexão entre a execução das ordens judiciais e o ato de interpretação judicial, por meio de hierarquias relativamente inflexíveis de pronunciamentos judiciais e obrigações firmes da parte dos agentes públicos 
encarregados de cumpri-los. Os juízes estão assim tanto separados como inextrincavelmente ligados aos atos que eles autorizam. (COVER, 1986b, p. 1627).

Essa circunstância é celebrada por Cover como "algo intrínseco a qualquer sucesso possível na tarefa de domesticar a violência” (COVER, 1986b, p. 1628). Cover destaca aqui a importância das regras que Hart (2006) chamou de secundárias, que orientam a "ordem hierárquica de vozes judiciais”, e assinalam os defeitos de um modelo de interpretação judicial que se concentra no trabalho de uma única mente coerente e consistente”. (COVER, 1986b, p. 1625).

Por mais coerente que seja, uma única mente não é capaz, segundo Cover, de carregar a "força da violência coletiva” que caracteriza o direito não só como um caso particular de violência, mas também de interpretação. Cover admite que a decisão de um "Hyporcules" provavelmente será mais articulada e coerente que uma decisão coletiva de vários juízes. Mas diante da tarefa de domesticar a violência do direito, prefere sacrificar as expectativas de se atingir um significado comum do que descartar as regras secundárias que instituem uma estrutura de múltiplas vozes para a tomada de decisões. Assim, Cover aceita que as consequências de sua leitura sobre a interpretação jurídica não sejam muito animadoras: “Só nos resta, portanto, esse mundo real da organização do direito-como-violência, com decisões cujo significado, se for comum, provavelmente não será coerente - e se for coerente, provavelmente não será comum”. (COVER, 1986b, p. 1629).

Ainda que essa postura pode ser vista como problemática para o próprio projeto de reconstrução de universos normativos de Nomos e Narrativa, o Cover de Violência e a Palavra não está disposto a ocultar as conclusões de seu reconhecimento sobre a centralidade da violência no direito:

\footnotetext{
Sejamos então explícitos. Ainda que seja um pensamento desagradável que dor e morte estejam no centro da interpretação jurídica, que assim seja. Não seria melhor se houvesse apenas uma comunidade argumentativa formado por leitores e escritos de textos - de intérpretes. Na medida em que dor e morte sejam parte de nosso mundo político, é essencial que elas estejam no centro do direito. A alternativa é verdadeiramente inaceitável: que eles estejam dentro de nossa política, mas fora da disciplina das regras de decisão coletiva e dos esforços individuais para atingir resultados por meio dessas regras. É algo intrínseco a qualquer sucesso possível na tarefa de domesticar a violência. (COVER, 1986b, p. 1628).
}

Esse raciocínio aponta que a experiência da interpretação jurídica é marcada, inevitavelmente, por ao menos dois "limites trágicos” à obtenção de significados comuns no direito. Primeiro, há um limite prático que resulta da organização social da violência jurídica, e 
que prescreve que a "responsabilidade pela violência deve ser compartilhada para que se possa exercê-la de forma segura e efetiva” (COVER, 1986b, p. 1628), o que envolve uma gama de atores sociais e não o trabalho de uma única mente judicial. Por outro lado, há um limite ainda mais profundo, fruto do caráter díspar das experiências envolvidas nos dois polos da interpretação jurídica:

\footnotetext{
Autor e vítima da violência organizada terão experiências significativas dolorosamente desiguais. Para o autor, a dor e o medo são remotos, irreais e amplamente não compartilhados. Por esse motivo, quase nunca fazem parte de artefatos interpretativos tais como a opinião judicial. Por outro lado, a justificação da violência é importante, real e cuidadosamente cultivada para aqueles que a impõem. Para a vítima, inversamente, a realidade e a significância da justificação da violência retrocedem de forma proporcional à esmagadora realidade de dor e de medo sofridos. (COVER, 1986b, p. 1629).
}

Assim, com o mesmo tom sombrio que utilizou ao invocar o "campo de dor e morte" no começo do ensaio, Cover (1986b, p. 1629) conclui: "Entre a ideia e a realidade do significado comum cai a própria sombra da violência do direito”.

As experiências da organização social do direito como significado e como violência parecem colidir frontalmente, e não houve mais tempo para que Cover, morto poucos meses após a publicação de Violência e a Palavra, pudesse responder aos questionamentos que esse confronto - talvez o mais fundamental de sua obra - suscita. A partir desse ponto, restaram apenas especulações, críticas e comentários. Há quem considere a tentativa de Cover de conciliar direito e violência como uma vã esperança (SARAT; KEARNS, 2001); há quem enxergue problemas cruciais em sua análise, embora reconheça seus méritos (SIMON, 2001); há quem procure ressignificar o “campo de dor e morte” do direito como a nossa única experiência possível em termos de significado comum (CONSTABLE, 2001); por fim, há quem veja Cover como um autor fundamental para entender que o direito é necessário para entender o nosso sofrimento, vendo o direito como a constante transgressão de si mesmo (McVEIGH et. al., 2001; MINOW, 1987).

Não cabe aqui debater sobre cada um desses caminhos, senão apontá-los como forma de demonstrar que o pensamento de Cover permanece vivo e - o que ao mesmo tempo surpreende e encoraja quem se propõe a estudá-lo - ainda pouco explorado. 


\section{CONSIDERAÇÕES FINAIS}

A difícil conciliação entre direito e violência, considerada como incompleta ou insatisfatória dentro da obra de Cover, poderia ser vista, em um sentido mais amplo, como um problema que afeta qualquer reflexão teórica sobre a legitimidade do direito. Como questão fundamental que é, esse não é um aspecto contraditório apenas dentro pensamento de Cover, mas dentro da própria existência humana. Estamos permanentemente imbricados na tarefa de construir sentido, mas nem sempre nossas visões sobre o mundo podem ser concretizadas na realidade compartilhada, no nomos que habitamos. Cover nos ensina que há um limite trágico - ainda que impreciso - entre o significado que podemos atingir e a violência - física ou epistêmica - que teremos de empregar. Essa parece ser a grande lição a ser tirada dos movimentos aparentemente contraditórios de Nomos e Narrativa e Violência e a Palavra: aceitar a circunstância de que o significado jurídico sempre estará relacionado aos domínios do controle social é fundamental para qualquer tentativa de coordená-lo ou de resistir a ele.

A concepção jurídica de Cover não se trata da questão de juridicizar ou desjuridicizar a vida social, mas de perceber que o direito é uma forma ou meio de organização social que está para além do que as estruturas institucionais entendem e determinam como direito vigente. Não apenas construímos instituições, consultamos leis, estudamos direito; nós vivemos em um espaço normativo. Isso pode parecer um exagero, mas para constatar a validade dessa afirmação basta olhar para as comunidades que precisam resistir ao direito oficial para viver. Direito não é apenas a autoridade sobre ele, mas também o significado que ele produz. O direito é recurso significativo, um artefato social, uma linguagem comum ou um instrumento para orientar nossa conduta no mundo presente e construir pontes para o futuro. E é tudo isso - conforme Cover nos recorda fortemente - à sombra de sua própria capacidade de gerar violência.

\section{REFERÊNCIAS}

BERGER, Peter; LUCKMANN, Thomas. A construção social da realidade: tratado de Sociologia do Conhecimento. 33. ed. Petrópolis: Vozes, 2011.

CALABRESI, Guido et al. Tributes to Robert M. Cover. Yale Law Journal, New Haven, v. 96, n. 8, p. 1699-1724, 1987.

CONSTABLE, Marianne. The silence of the law: justice in Cover's "field of pain and death". In: SARAT, Austin (Ed.). Law, violence, and the possibility of justice. Princeton, New Jersey: University Press, 2001. 
COVER, Robert. Federal judicial review of state welfare practices. Columbia Law Review, New York, v. 67, n. 1, p. 84-129, 1967.

COVER, Robert. Justice accused: antislavery and the judicial process. New Haven: Yale University Press, 1975.

COVER, Robert. The bonds of constitutional interpretation: of the word, the deed and the role. Georgia Law Review, Athens, v. 20, n. 4, p. 815-834, 1986a.

COVER, Robert. The folktales of justice: tales of jurisdiction. Capital University Law Review, Columbus, v. 14, n. 5, p. 179-204, 1985.

COVER, Robert. The origins of judicial activism in the protection of minorities. Yale Law Journal, New Haven, v. 91, n. 7, p. 1287-1316, 1982.

COVER, Robert. The Supreme Court, 1982 Term - Foreword: Nomos and Narrative. Harvard Law Review, Cambridge, v. 97, n. 1, p.4-68, 1983.

COVER, Robert. The uses of jurisdictional redundancy: interest, ideology, and innovation. William \& Mary Law Review, Williamsburg, v. 22, n. 4, p.639-682, 1981.

COVER, Robert. Violence and the word. Yale Law Journal, New Haven, v. 95, n. 1, p. 16011629, 1986b.

COVER, Robert. Your law-baseball quiz. In: MINOW, Martha; RYAN, Michael; SARAT, Austin (Orgs.). Narrative, violence, and the law: The Essays of Robert Cover. Ann Arbor: Michigan University Press, 1995.

GRIFFITHS, John. What is Legal Pluralism? The Journal of Legal Pluralism and Unofficial Law, [S.I.], v. 18, n. 24, p. 1-55, 1986.

ETXABE, Julen. The legal universe after Robert Cover. Law and Humanities, Coventry, v. 4, n. 1, p. 115-147, 2010.

McVEIGH, Shaun; RUSH, Peter; YOUNG, Alison. A judgment dwelling in law: violence and the relations of legal thought. In: SARAT, Austin (Ed.). Law, violence, and the Possibility of Justice. Princeton, New Jersey: University Press, 2001.

MINOW, Martha. Interpreting rights: an essay for Robert Cover. Yale Law Journal, New Haven, v. 96, n. 8, p. 1860-1915, 1987.

SARAT, Austin; KEARNS, Thomas. Making peace with violence: Robert Cover on law and legal theory. In: SARAT, Austin (Ed.). Law, violence, and the possibility of justice. Princeton, New Jersey: University Press, 2001.

SHAPIRO, Fred; PEARSE, Michelle. The most-cited law review articles of all time. Michigan Law Review, Ann Arbor, v. 110, n. 8, p. 1483-1520, 2012. 
SIMON, Jonathan. The vicissitudes of law's violence. In: SARAT, Austin (Ed.). Law, violence, and the possibility of justice. Princeton, New Jersey: University Press, 2001.

STEINER, George. Depois de Babel: questões de linguagem e tradução. Curitiba: Editora da UFPR, 2005.

WIZNER, Stephen. Repairing the world through law: a reflection on Robert Cover's social activism. Cardozo Studies in Law and Literature, New York, v. 8, n. 1, p. 1-14, 1996. 